\section{Hechos y valores. Hacia una psiquiatría crítica}

Facts and values.

To a critical psychiatry

Estimado editor:

George Engel criticaba el modelo biomédico, reduccionista, que imperaba en la sociedad. En contrapartida, sostenía un modelo más holístico y humanista que denominó bio-psico-social. En la actualidad, el modelo imperante es el biomédico que concibe a un cuerpo enfermo pero no a una persona con un problema. Por eso, hemos de reivindicar las ideas de Engel. Hacer esto pasa por ejercer una psiquiatría crítica basada en presupuestos éticos, técnicos y científicos centrados en el paciente y su cuidado.

Esa perspectiva bio-psico-social ha de estar guiada por hechos y valores, a saber: conocimiento científico y deseos, preferencias, etc. del paciente.

En ese entramado, subyacen los principios de la bioética: autonomía, beneficencia, no-maleficencia y justicia. En efecto, todo acto clínico busca el mayor beneficio y la evitación de daños; sin embargo, asumir un enfoque paternalista implica no tener en cuenta la opinión de la persona. Actualmente, vamos hacia modelos más integrales basados en la autonomía y la dignidad. Las leyes sanitarias indican la obligación de los profesionales y el derecho de los pacientes a recibir información, a recabar el consentimiento informado, a respetar unas voluntades anticipadas, etc.

Pero no se trata de una psiquiatría "a la carta". Los pacientes han de decidir responsablemente, con asesoramiento clínico. Un enfoque paternalista, por muy técnico y especializado que sea, si no cuenta con la opinión del paciente puede conllevar mala praxis por no respetar su voluntad. Pero un exceso de autonomía sin conocimientos clínicos puede incurrir en imprudencia y en desenlaces fatales por mala planificación. Por tanto, el ideal es tomar decisiones compartidas.

En esa relación asistencial, los profesionales han de disponer de unas virtudes (compasión, cuidado, prudencia...) que indiquen el compromiso para con el paciente. Entre ellas, la empatía es imprescindible para apreciar el sufrimiento del paciente y romper con el estigma y la discriminación asociado a los trastornos mentales.

Además, los profesionales deben adoptar una actitud crítica, propia de la ética, en la relación asistencial y en aquello que pide la sociedad. Los principios éticos no son absolutos, sino prima facie, así que en cada caso hay que deliberar sobre el caso. Esto implica reflexión para volver a debatir o incluso potenciar ciertos temas tabúes. Por un lado, es curioso que aunque aceptamos los ingresos involuntarios, en cuanto al tratamiento ambulatorio involuntario no lo tenemos tan claro. En efecto, incluso admitiendo que en muchos países europeos y la gran mayoría de los Estados de los Estados Unidos lo practican, en España resulta un tema complicado porque quebranta aspectos fundamentales sobre la libertad de la persona, razón por la cual actualmente hay abierto un gran debate en torno a su legislación y su aplicabilidad. En cualquier caso, si queremos luchar por la dignidad de la persona, quizás sería oportuno volver a discutir sobre ello.

Por otro lado, hemos de dar voz a los pacientes psiquiátricos y presuponer que son competentes y que quieren decidir, y no partir de que no lo son. Tenemos, pues, la obligación ética de llevar a cabo una pedagogía sobre el consentimiento informado, las voluntades anticipadas y los planes de decisión anticipada. Así pues, si es competente hemos de aceptar su decisión, sea aceptación o rechazo de tratamientos. $Y$ en aquellos casos en los que no tenga competencia suficiente para la toma de decisiones, hemos de ayudarles a decidir. Así lo ratifica la Convención sobre los derechos de las personas con discapacidad promovida por la Organización Naciones Unidas.

Por todo ello, cabe concluir que la psiquiatría no puede ser reduccionista, biologicista ni paternalista. Hay que dar el protagonismo a los pacientes psiquiátricos, pues las personas cada vez más quieren ser partícipes en las decisiones sanitarias. $\mathrm{Y}$ en aquellos casos en los que no sea capaz de tomar decisiones por sí mismo, hemos de ayudarles 
para que su autonomía y voluntad sea llevado a cabo. Con ello, hemos de pasar de modelos basados en la beneficencia y la no-maleficencia, a tomar decisiones fundamentadas en la autonomía y la dignidad, centradas en y para la persona, tomando como ejes centrales hechos y valores.

Dr. Sergio Ramos Pozón Máster en Bioética. Doctor en Filosofía. Universidad de Barcelona (España) Fundació Víctor Grífols i Lucas (Barcelona)

Correspondencia:

Dr. Sergio Ramos Pozón

E-mail: ramospozon@hotmail.com 